\title{
A systematic theoretical study on the stability of a series of dialkyl peroxides to light and heat
}

\author{
Wenlan Chen ${ }^{1}$, Lu Chen ${ }^{1}$, and Shaohui Zheng ${ }^{1}$ \\ ${ }^{1}$ Southwest University
}

May 6, 2020

\begin{abstract}
Dialkyl peroxides may decompose under heating and illumination conditions, and consequently cause an explosion or fire possibility. However, they can promote diesel-degraded branching reaction, enhance diesel spontaneous combustion ability, and accelerate the chain reaction of fuel combustion. In this study, one series of dialkyl peroxides, i.e. methyl, ethyl, isopropyl, and di-t-butyl peroxide, which have different numbers of terminal methyl groups, have been modeled. We have systematically explored their stabilities under heating and illumination conditions by using CCSD(T), DFT/TDDFT, and variational transition state theory. We focus on the rate constants of thermal dissociation of peroxide bonds and absorption spectra because previous experimental and calculated thermal kinetic parameters are not consistent and the absorption spectra of these compounds are few. Based on the calculated data including rate constants and simulated absorption spectra, we find out that di-t-butyl peroxide is the best candidate among four compounds considering the stability under both heat and light. The most striking finding is that the previous assumption that the activation energy of O-O decomposition equals O-O bond energy may be wrong.
\end{abstract}

\section{Hosted file}

dtbp-iqc.docx available at https://authorea.com/users/316960/articles/448525-a-systematictheoretical-study-on-the-stability-of-a-series-of-dialkyl-peroxides-to-light-and-heat 